\title{
Monokoryonik Monoamniyotik İkiz Gebeliklerde Tersiyer Bir Merkezdeki Deneyimimiz
}

\section{Management of Monochorionic Monoamniotic Twin Pregnancy Experience of a Tertiary Center \\ Engin ÖZTÜRK ${ }^{1}{ }^{(D)}$, Emre EKMEKÇi 1}

1 Şanlıurfa Eğitim Araştırma Hastanesi Kadın Hastalıkları ve Doğum Kliniği, Şanlıurfa, Türkiye.

Öz.

Amaç: Monokoryonik monoamniyotik ikiz gebeliklerin (MKMA) kliniğimizdeki uyguladığımız yönetim şekli ile gebelik sonuçlarının değerlendirilmesi, bu gebeliklerdeki komplikasyonların tanımlanması. Materyal ve metod: Çalışmaya üç yıllık süreçte kliniğimizde takip edilen ve sonuçlandırılan MKMA ikiz gebelikler dahil edildi. Veriler retrospektif olarak toplandı, çalışmaya dahil edilen gebeliklerin gebelik sonuçları, monokoryonisiteye spesifik gebelik komplikasyonlar ve bu gebeliklerdeki konjenital malformasyonlar kaydedildi.

Bulgular: Üç yıllık süreçte toplam 12 MKMA ikiz gebeliğin kliniğimizde takip ve yönetimi uygulanmıştı. Üç olguda ikiz eşi doğum öncesi dönemde intrauterin fetal kayıp ile komplike olmuştur. Bir olguda her iki fetüsün intrauterin kaybı ile sonuçlanmıştır. Hiçbir olguda monokoryonisite spesifik komplikasyon ile karşılaşılmadı. Bir olguda her ikizde diskordan konjenital malformasyonlar mevcuttu.

Sonuç: MKMA gebelikler nadir fakat perinatal tıpta en karmaşık ve yönetim açısından tartışmalı konulardandır. Nasıl yönetilmesi ve ne zaman teslim edileceği konusunda henüz netlik yoktur. Bu çalışmada kliniğimizdeki yönetim protokolümüzle ilgili deneyimimizi bildirdik.

Anahtar Kelimeler: Monokoryonisite, Monoamniyotik ikiz, Monozigosite

\section{Abstract}

Background: Evaluation of obstetric outcomes of monochorionic monoamniotic twin pregnancies (MCMA) with our management method that we apply in our clinic, and to describe the complications in these pregnancies.

Materials and Methods: MCMA twin pregnancies that are followed and finalized in our clinic in three years period were included in the study. The data were collected retrospectively, pregnancy outcomes of the pregnancies included in the study, pregnancy complications specific to monochorionicity and congenital malformations in these pregnancies were recorded.

Results: A total of 12 MCMA twin pregnancies were followed and managed in our clinic over a threeyear period. In three cases, intrauterine death of co-twin was complicated in prenatal period. In one case, it resulted in intrauterine demise of both fetuses. No monochorionicity-specific complication was encountered in any case. Discordantly congenital malformations were present in both twins in one pregnancy

Conclusion: MCMA pregnancies are rare but one of the most complex and controversial issues in terms of management in perinatal medicine. There is no clarity yet on how to manage and when to deliver. In this study, we reported our experience with our management protocol in our clinic.

Key words: Monochorionisity, Monoamniotic pregnancy, Monozygosity

\section{Sorumlu Yazar I \\ Corresponding Author}

\section{Op.Dr. Engin Öztürk}

Şanlıurfa Eğitim Araştırma Hastanesi Kadın Hastalıkları ve Doğum Kliniği, 63250 , Şanlıurfa, Türkiye

e-mail: dr.enginozturk@hotmail.com Tel: +90505-062-52-87

Geliş tarihi / Received: 26.10.2020

Kabul tarihi / Accepted: 26.11.2020

DOI: $10.35440 /$ hutfd. 816830 


\section{Giriş}

Monokoryonik ikiz gebelikler günümüzde tüm ikiz gebeliklerin yaklaşık olarak \%20'sini oluşturmakla birlikte, infertilite tedavisi gibi dikoryonik ikiz gebelikler için artmış prevalansla ilişkili faktörlerle ilişkili olmayıp tüm gebelikler içerisinde prevalansı neredeyse sabittir (1). Monokoryonik ikiz gebelikler monokoryonisiteye spesifik komplikasyonlar, ikizden ikize transfüzyon sendromu (TTTS), selektif intrauterin gelişme geriliği (sIUGR), twin anemi-polisitemi sekans (TAPS), TRAP ile ilişikli olmakla birlikte, MKMA ikiz gebelikler daha da riskli bir grup olarak yer almaktadır. Monokoryonik ikiz gebeliklerin \%5'i ve tüm gebelikler içerisinde 10000 'de bir prevalansa sahip MKMA ikiz gebelikler ilave olarak monoamniyonisiteye özel riskler nedenli daha da önem arz etmektedir (2). Artmış konjenital malformasyon oranları ve kordon dolaşıklığı (cord entanglement) gibi özel durumların da varlığı nedenli daha önceleri çok daha yüksek olan 20.gebelik haftası ve üzerinde fetal kayıp oranları halen $\% 15$ olarak devam etmektedir (3).

Konjenital malformasyonlar MKMA ikiz gebeliklerde tekil gebeliklere, dikoryonik ikizlere ve hatta monokoryonik ikiz gebeliklere oranla artmış oranda karşılaşılmaktadır. MKMA ikiz gebeliklerin yüzde 7 ile 28'inde, diamniyotik monokoryonik ikiz gebeliklerin yüzde 6'sında majör anomaliler bildirilmiştir. Bu yüksek anomali oranları da fetal kayıp ile ilişkilidir. Anomaliler sadece $\% 25$ oranında her iki fetüste konkordandır. \%75 sadece tek fetüs ile ilişkilidir $(4,5)$.

Yapışık ikizler, 100.000 doğumda 1.5 oranında olmakla birlikte nadir bir monokoryonik monoamniyotik ikiz gebeliktir (6).

Perinatal mortaliteyi azaltmaya yönelik gebeliğin sonlandırma zamanına yönelik standart bir yaklaşım belirlenmemiştir. Gebeliğin sezaryenle sonlandırıması gereksinimi kabul edilmiş bir yaklaşım olarak belirlenmiş olmasına rağmen, sezaryen zamanlamasına yönelik genel yaklaşım 3234. gebelik haftaları arasında yapılması şeklinde olmakta$\operatorname{dir}(7)$.

Biz bu çalışmada kliniğimizde MKMA ikiz gebeliklerin yönetiminde uyguladığımız yönetim şeklimiz ile klinik deneyimimizi bildirdik.

\section{Materyal ve Metod}

Çalışmamız Şanlıurfa Eğitim ve Araştırma Hastanesi, Kadın Hastalıkları ve Doğum Kliniği'nde yapılmıştır. Retrospektif olarak toplanan veriler Temmuz 2017-Ağustos 2020 tarihleri arasında kliniğimizde MKMA ikiz gebelik tanısıyla takibi yapılan ve gebeliği sonlandırılan hastalardan elde edilmiştir. Çalışmanın yapılması ile ilgili etik kurul onayı Harran Üniversitesi Tıp Fakültesi Klinik Araştırmalar Etik Kurulu'ndan alınmıştır (31/08/2020 tarih, 15 nolu oturum 13 sayılı kurul kararı). Kliniğimiz Türkiye'de en yüksek doğum sayısına sahip ve yılda yaklaşık 40000 doğum ile yoğun bir tersiyer merkezdir. Monokoryonisite ve monoamniyonisitenin tanısı ilgili alanda deneyimli bir perinatoloji yan dal uzmanı tarafından konulmuştur (Ekmekci E.). Monoamniyonisitenin tanısı ikizler arası amniyotik membranın olmaması, tek bir plasenta varlığı ve fetal cinsiyetlerin aynı olması ile konuldu (Şekil 1). Yapışık ikizler çalışmaya dâhil edilmedi.

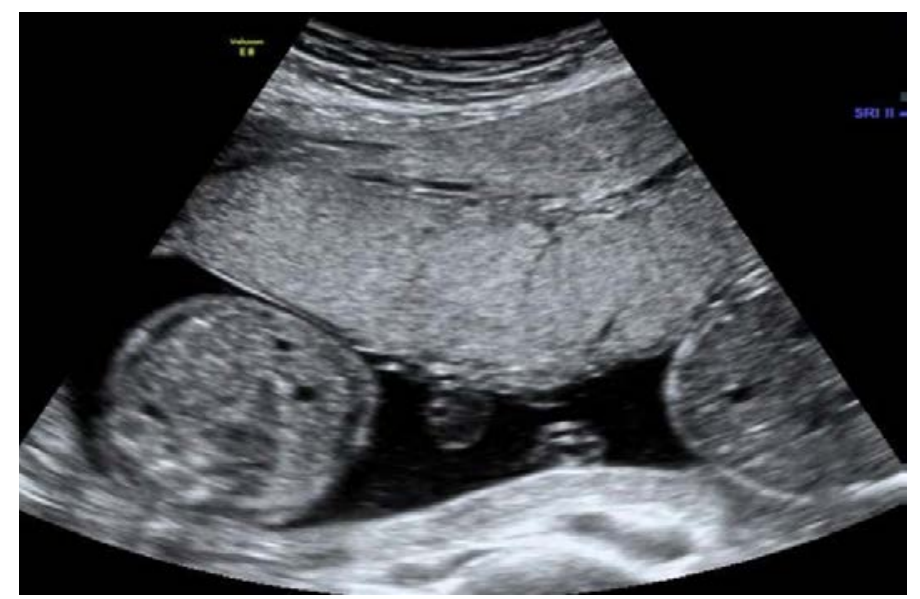

Şekil 1. MKMA ikiz gebeliğin ultrasonografik tanıSı MKMA: Monokoryonik monoamniyotik

Hastaların takibi kliniğimiz perinatoloji polikliniğinde yapılmış olup, tanının konulması sonrasında gebeliğin 24. haftasına kadar iki haftada bir daha sonrasında ise haftalık olarak perinatoloji polikliniğimizde görülmüşlerdir. 26. gebelik haftasından itibaren muayenelerde NST yapılmıştır. MKMA ikiz gebeliklerin takibinde kliniğimizde uyguladığımız protokole göre, 31. gebelik haftasına her iki fetüsün canlı olarak ulaştığı gebeliklerde, hastanın kliniğe yatışı yapılmakta ve akciğer matürasyonu indüksiyonu için betametazon profilaksisi (24 saat ara ile $12 \mathrm{mg}$ betametazon) yapılmaktadır. Bir haftalık yatarak takip sonrasında 32.gebelik haftasında gebelik sezaryenle sonlandırımaktadır.

Hastaların demografik verileri, tanı anında ve doğum zamanındaki gebelik yaşları, doğum endikasyonları, konjenital malformasyon varlığı, intrauterin fetal kayıp durumları ve her olgunun doğumuna kadar olan toplam takip süreleri kaydedildi.

\section{Bulgular}

Üç yıllık süreç içerisinde toplam 14 MKMA ikiz gebelik tanısı konulmuştur. Bunlardan iki tanesi yapışık ikiz olması nedenli çalışma dışında tutulmuştur. Tanı anında ortalama maternal yaş 31.8 (25-38 yaş) idi. Altı olguda tanı ilk trimesterde konulmuş, beş olguda tanı erken ikinci trimesterd e(15-21 hafta) konulmuş ve bir olguda tanı 35 . gebelik haftasında konulmuştur. 35. gebelik haftasında tanı alan olgu haricinde diğer tüm olgular için takip ve 32. gebelik haftasında gebeliğin sonlandırıması planlanmıştır. 35 . haftada tanı alan olguda gebelik hemen sonlandırımıştır. Bir olguda her iki fetusta diskordan fetal anomaliler saptanması nedenli gebelik 21. haftada termine edilmiştir (tek fetusta kistik higroma ve hidrops fetalis, diğer fetusta omfalosel). 
Takip edilen 10 gebeliğin üç tanesinde ikiz eşi takip sürecinde spontan intrauterin fetal kayıpla sonuçlanmıştır. İkiz eşi intrauterin fetal kayıp bir olguda 21. haftada, bir olguda 29. haftada ve bir olguda 30 . gebelik haftasında gerçekleşmiştir. Takip altında olan olgularımızın hiçbirinde monokoryonisite spesifik komplikasyonlar (TTTS, sIUGR, TRAP, TAPS) ile karşılaşılmadı. Intrauterin fetal kayıp ile komplike tüm gebeliklerde kordon dolaşıklı̆ı sezaryen sırasında konfirme edilmiştir (Şekil 2). İntrauterin fetal kayıp (IUFD) ile komplike bir gebelikte preterm doğum eylemi nedeniyle gebelik 31. haftada sonlandırımış̧ır. Her iki fetüsün sağ olarak 32. gebelik haftasına ulaştığı sekiz olguda gebelik 32. haftada sezaryenle sonlandırımışıtır. IUFD ile komplike bir olguda gebelik 34. haftada sonlandırılmış ve diğer olguda yoğun maternal anksiyete nedenli gebelik 32 . haftada sonlandırımıştır. IUFD ile komplike gebeliklerde doğum sonrası yaşayan fetüste nörolojik morbidite ile karşılaşımamıştır (Tablo 1).

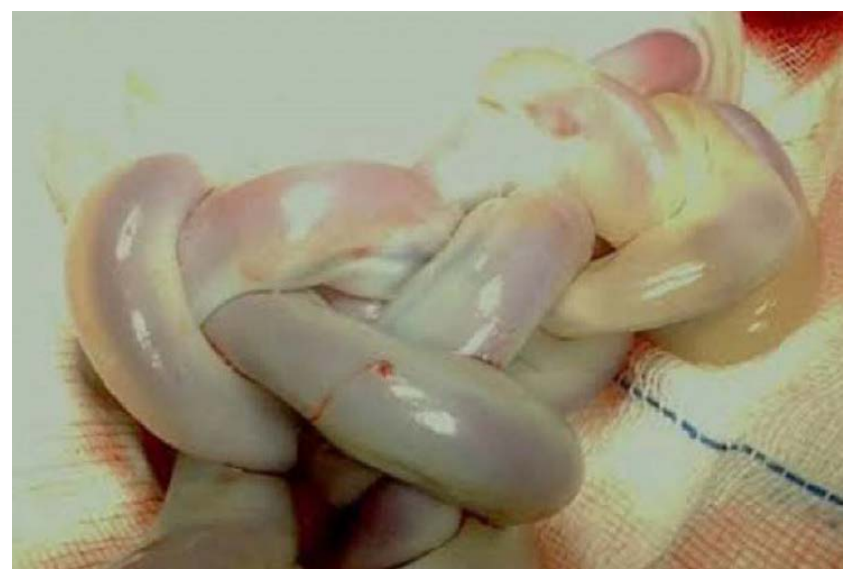

Şekil 2. MKMA ikiz gebeliklerde sık karşılaşılan kordon dolaşıklığı (cord entanglement)

MKMA: Monokoryonik monoamniyotik

Tablo 1. MKMA ikiz gebeliklerde sonuçlar

\begin{tabular}{|l|l|}
\hline Yapışık ikiz & $2 / 14(\% 14)$ \\
\hline 32. gebelik haftası öncesi ikiz eşi IUFD & $3 / 11(\% 27,2)$ \\
\hline Konjenital malformasyon & $1 / 12(\% 8,3)$ \\
\hline 32. gebelik haftası öncesi spontan prematürite & $1 / 11(\% 9,1)$ \\
\hline Median doğum haftası & $32(31-35$ hafta) \\
\hline Monokoryonisite spesifik komplikasyon & ---- \\
\hline Toplam canlı yenidoğan / başlangıç fetüs sayısı & $19 / 24(\% 79)$ \\
\hline IUFD: İntrauterin fetal kayıp. \\
MKMA: Monokoryonik monoamniyotik.
\end{tabular}

\section{Tartışma}

Bu çalışmada nadir bir ikiz gebelik şekli olan MKMA ikiz gebeliklerle ilgili klinik deneyimlerimizi ve sonuçlarımızı paylaştık. MKMA ikiz gebelikler tüm spontan elde edilen gebeliklerin on binde 1'ini, ikiz gebeliklerin \%1'ini ve monokoryonik ikiz gebeliklerin \% 5 'ini oluşturmakta ve nadir olarak karşılaşılmaktadır (8). Biz çalışmamızda tek merkezli bir çalışma olması ve kliniğimize bölgeden ve çevre illerden refere edilen hastaların sık olması nedeniyle yanlış değer- lendirme olacağından prevalans hesaplamadık. Nadir olması nedeniyle konu üzerine çalışmalar sınırlı olsa da en geniş kapsamlı ve yakın zamanlı çalışma İngiltere'de 2000-2013 yılları arasını kapsayan ve çok merkezli bir çaIışma olan ve 59 MKMA ikiz gebelik ile yürütülen çalışmadır. Bu çalışmada prevalans on binde 1.3 olarak ve hatta canlı doğumla sonuçlanabilen gebelik prevalansı yüz binde 8.3 olarak bildirilmiştir (4).

Tek plasenta olmasına rağmen MKMA ikiz gebeliklerde monokoryonisite spesifik komplikasyonlar diamniyotiklere kıyaslandığında belirgin daha az olarak karşılaşılmaktadır. TTTS riski diamniyotiklere kıyaslandığında her ikisi de monokoryonik plasentaya sahip olsa da, \%2'ye \%6 gibi bir oran ile daha az oranda saptanmıştır (9). Bizim hasta popülasyonumuzda vaka sayısı sınırı olsa da takip altındaki 11 gebeliğin hiçbirinde monokoryonik plasenta ilişkili komplikasyon ile karşılaşmadık.

MKMA ikiz gebeliklerde majör konjenital anomali insidansı tekil ve diamniyotik ikiz gebelikler ile kıyaslandığında belirgin oranda artmış saptanmaktadır. Kardiyak anomali oranları diğer tüm gebeliklere göre artmıştır. Anomalilerin sadece $\% 25$ 'inin konkordan olması ve $\% 75^{\prime}$ inin diskordan olması etyolojide plasental anastamozlarla ilişkiyi düşündürmektedir (5). Bizim çalışmamızda, 12 olguluk serinin bir tanesinde diskordan konjenital anomali saptandı.

Kordon dolaşıklığının ultrasonografik olarak tespiti monoamniyotik ikizler için patognomoniktir ve ilk trimesterin sonlarından itibaren gözlenebilmektedir. Neredeyse tüm MKMA ikiz gebeliklerde karşılaşımaktadır (10). Başlarda esnek olan dolaşıklık, gebeliğin ilerlemesiyle sıkı hal almaktadır. Buna rağmen geniş bir derlemede kordon dolaşıklığı olan MKMA ikiz gebeliklerin \%89'unda fetüslerin canlı olarak doğurtulduğu bildirilmiştir (11). Bizim çalışmamıza dahil olan gebeliklerin tamamında sezaryen sırasında dolaşık kordon doğrulanmış olmakla birlikte üç olguda ikiz eşinin intrauterin kaybı gerçekleşmiştir. Kordon dolaşıklığının MKMA ikiz gebeliklerde intrauterin fetal kayıpla ilişkisi yüksek görünse de neden sadece bir kısmında fetal kayıpla sonuçlanmakta birçoğunda ilişkisiz görünmekte olduğu bilinmemektedir.

Intrauterin fetal kayıpları önlemek amaçlı 28. gebelik haftasından itibaren hastanede yatarak takip edilen gebelerle, ayaktan izlenen ve 32 . haftada gebeliği sonlandırılan hastaların karşılaştırılığı küçük çaplı bir çalışmada fetal kayıp oranları $\% 3$ ve $\% 7$ olarak saptanmış ve yatarak takibin faydalı olduğu bildirilmiştir (12). Bizim kliniğimizde uyguladığımız yönetim şekli ile üç intrauterin fetal kaybın iki tanesi 28. gebelik haftası sonrasında gerçekleşti. Yatarak takip uygulanmasının kayıpları önleyip önleyemeyeceği konusunda net yorum yapılamamaktadır.

Çalışmamızın en önemli özelliği sabit bir yönetim şekli ile MKMA ikiz gebeliklere ait sonuçları tek merkezden görebilme imkânı sağlamasıdır. En önemli limitasyonu hasta 
sayısının azığı olmakla birlikte nadir bir ikiz gebelik tipi olması nedeniyle tek merkez için üç yıllık süreçte oldukça yeterlidir. Bir diğer limitasyon ise hastalarımızın büyük kısmını refere edilen hastalar oluşturduğundan çalışma popülasyonumuz erken dönem intrauterin kayıpları ya da tanı konulmadan takip edilebilecek olan hastaları içermemektedir.

Sonuç olarak, MKMA ikiz gebeliklerin yönetiminde standart bir yaklaşım yoktur. Her klinik kendi yönetim şeklini uyguluyor olsa da spontan intrauterin fetal kayıpların önüne geçilebilecek net bir klinik yaklaşım ortaya konulamamıştır. Biz de yapmış olduğumuz bu çalışma ile kendi kinik deneyimimizi sunduk.

Etik onam: Çalışmanın yapılması ile ilgili etik kurul onayı Harran Üniversitesi Tıp Fakültesi Klinik Araştırmalar Etik Kurulu'ndan alınmıştır (31/08/2020 tarih, 15 nolu oturum 13 sayılı kurul kararı).

\section{Kaynaklar}

1. Black M, Bhattacharya S, editors. Epidemiology of multiple pregnancy and the effect of assisted conception. Seminars in Fetal and Neonatal Medicine; 2010;15(6):306-312.

2. Shub A, Walker SP. Planned early delivery versus expectant management for monoamniotic twins. Cochrane Database Syst Rev. 2015 Apr 15;4:CD008820. doi: 10.1002/14651858.CD008820.pub2. Review.

3. Morikawa M, Yamada T, Yamada T, Sato S, Minakami H. Prospective risk of intrauterine fetal death in monoamniotic twin pregnancies. Twin Research and Human Genetics. 2012;15(4):522-6.

4. Glinianaia SV, Rankin J, Khalil A, Binder J, Waring G, Sturgiss SN, et al. Prevalence, antenatal management and perinatal outcome of monochorionic monoamniotic twin pregnancy: a collaborative multicenter study in England, 2000-2013. Ultrasound in Obstetrics and Gynecology. 2019;53(2):184-92.

5. Post A, Heyborne K. Managing monoamniotic twin pregnancies. Clinical obstetrics and gynecology. 2015;58(3):643-53.

6. Mutchinick OM, Luna Muñoz L, Amar E, Bakker MK, Clementi M, Cocchi G, et al., editors. Conjoined twins: a worldwide collaborative epidemiological study of the International Clearinghouse for Birth Defects Surveillance and Research. American Journal of Medical Genetics Part C: Seminars in Medical Genetics; 2011;157(4):274-287.

7. Van Mieghem T, De Heus R, Lewi L, Klaritsch P, Kollmann M, Baud $D$, et al. Prenatal management of monoamniotic twin pregnancies. Obstetrics and Gynecology. 2014;124(3):498-506.

8. Derom C, Vlietinck R, Derom R, Van den Berghe H, Thıery M. Population-based study on sex proportion in monoamniotic twins. The New England Journal of Medicine. 1988;319(2):119-20.

9. Hack K, van Gemert M, Lopriore E, Schaap A, Eggink A, Elias S, et al. Placental characteristics of monoamniotic twin pregnancies in relation to perinatal outcome. Placenta. 2009;30(1):62-5.

10. Aisenbrey GA, Catanzarite VA, Hurley TJ, Spiegel JH, Schrimmer DB, Mendoza A. Monoamniotic and pseudomonoamniotic twins: sonographic diagnosis, detection of cord entanglement, and obstetric management. Obstetrics and Gynecology. 1995;86(2):218-22.

11. Rossi A, Prefumo F. Impact of cord entanglement on perinatal outcome of monoamniotic twins: a systematic review of the literature. Ultrasound in Obstetrics and Gynecology. 2013;41(2):131-5.

12. D'Antonio F, Odibo A, Berghella V, Khalil A, Hack K, Saccone G, et al. Perinatal mortality, timing of delivery and prenatal management of monoamniotic twin pregnancy: systematic review and metaanalysis. Ultrasound in Obstetrics and Gynecology. 2019;53(2):166-74. 